Kathmandu, Nepal

marty@martylogan.net

Cite this as: $B M J$ 2021;373:n1569

http://dx.doi.org/10.1136/bmj.n1569

Published: 22 June 2021

\section{REPRODUCTIVE HEALTH}

\section{Lockdown in Nepal further strains supply of lifesaving maternal health drug}

\section{Supplies of misoprostol in Nepal have long been erratic, and covid-19 has squeezed them further, writes Marty Logan}

\section{Marty Logan freelance journalist}

Nepal entered a four month nationwide lockdown in March 2020, during which the number of women accessing maternal and sexual and reproductive health services saw a worrying drop. Births in hospital dropped by more than half, ${ }^{1}$ and stillbirths and neonatal mortality in hospital rose.

At the start of the lockdown, $72 \%$ of health facilities countrywide were providing safe abortion services, but that number fell to $61 \%$ in July, according to a survey by the UN Population Fund (UNFPA) and the Nepalese government.

Initially, some health facilities closed completely, or women assumed that they weren't operating. Lacking protective equipment, staff at some centres did not report for work, and many women were scared to visit health facilities in case they caught covid-19.

Transportation was often unavailable, and drugs and other commodities were in short supply.

One such drug is misoprostol, used to treat postpartum haemorrhage (PPH) or to induce medical abortion. A steroid that causes the uterus to contract, the drug has been transformative for women in childbirth: a 2012 study of randomised controlled trials comparing misoprostol with placebo in primary care or home delivery settings found that the drug reduced $\mathrm{PPH}$ by $24 \%$ and severe $\mathrm{PPH}$ by $41 \%$.

$\mathrm{PPH}$ is thought to cause one quarter of maternal deaths in Nepal, and is the number one cause of mortality for women who deliver at home. Shortages of misoprostol have been blamed for the deaths of many women post-delivery during the 2020 lockdown. In April 2020, Punya Poudel, chief of the Safe Motherhood unit at the Family Welfare Division, told the Kathmandu Post she was concerned that only 16 of 77 districts across the country had access to misoprostol. ${ }^{2}$

\section{Historic shortages}

Supply problems were not uncommon in Nepal before the pandemic, but even with the shortages, misoprostol is thought to have significantly improved maternal health in the country.

The first trials of the drug in Nepal started in 2005, looking at oral misoprostol for preventing PPH in home births (following a successful 2002 pilot study in Indonesia). At the time, maternal mortality in Nepal was 281 deaths per 100 ooo live births each year (down from 539 deaths in 1996 after improvements to the healthcare system). By 2016, with the deployment of misoprostol and other interventions, the figure was 239 (some way from the UN Sustainable Development Goal target of fewer than 70 by 2030).

By 2009-10 the government of Nepal had approved the use of misoprostol for women who were likely to deliver by themselves at home, to be supplied by Female Community Health Volunteers (FCHVs). The country's health department declared that misoprostol would be available in all districts within a year, but by 2020 , just 56 of 77 districts offered the drug.

A corruption scandal in 2014 didn't help. Eight health department officials were prosecuted for allegedly importing sub-par misoprostol at inflated prices. All were acquitted, but misoprostol became "a kind of controversial drug-no one wanted to take the lead in procuring it," says Swaraj Rajbhandari, a gynaecologist who worked with the Nepal Family Health Programme, which led the 2005 pilot project. Supply shortages became routine.

Other reasons for the programme's slow uptake were a "flavour of the month" tendency-championing a new approach for a short period and then shifting attention to the next project-and a focus on persuading women to give birth in health facilities rather than at home, without a skilled birth attendant. Rajbhandari says FCHVs were getting mixed messages from officials: “One group said, "Don't give (misoprostol) to pregnant women” (to encourage them to come to health facilities to give birth); another group said, "Give it to pregnant women."

In 2017, following Nepal's first elections under a responsibilities were transferred from central authorities to provincial or local officials, including procurement and distribution of misoprostol. But local governments appeared unprepared.

"In general, local governments did not have sufficient time and resources to strengthen their procurement capacity on lifesaving maternal and neonatal health commodities," a spokesperson for UNFPA Nepal told The BMJ in a statement, "It also depended on how much priority each local government had given to the health sector in general."

A survey of 12 districts in January 2020 found that none had misoprostol, says Surya Bhatta, executive director of One Heart Worldwide, an international non-profit organisation working in Nepal. federal governance system, some health 
"I think misoprostol is one of the most discussed matters in our office," he adds. "We talk about this a lot with local leaders, pregnant mothers, FCHVs during their monthly meetings, and with service providers in the health facilities. Even for the managers, in larger government forums, there is a lot of discussion happening, but the implementation side has a lot of holes to fill."

\section{Medical abortion}

Misoprostol was cleared for use in medical abortion in Nepal in 2008 and is included, with the drug mifepristone, in the government's authorised medical abortion kit. Sources told The $B M J$ it is also likely found in more than two dozen unauthorised medical abortion packs sold in pharmacies in the country.

Medical abortion was the method preferred by $72 \%$ of Nepali women seeking pregnancy termination, according to the 2016 Nepal Demographic and Health Survey. Of women who had a medical abortion, $71 \%$ used services provided by a doctor, nurse, or auxiliary nurse midwife, and $19 \%$ used a pharmacist or medical shop. The latter is illegal, but was permitted under interim guidelines issued by the Nepal government in response to the pandemic.

Maternal mortality has been in steep decline since abortion was legalised in 2002. But in 2020, access to services was reduced during pandemic restrictions. In province 2 in eastern Nepal, half of all health facilities stopped providing safe abortion services for five months, according to a survey by NGOs.

"Services for both surgical and medical abortion plummeted during the pandemic," says Satyajit Pradhan, of Marie Stopes International. "Even though it was considered an essential medical service, it wasn't always easy or comfortable trying to explain to headstrong policemen enforcing a roadblock to allow someone [in need of medical attention] to pass. We received many calls from desperate women who were asking our contact centre agents to speak and reason with policemen who were not budging."

UNFPA reported that just $46 \%$ of health facilities had a stock of abortion drug kits in April 2020, falling to $41 \%$ in July, and the scarcity of misoprostol in the three-pill pack sparked a scramble for stocks. After a government request, UNFPA and One Heart Worldwide sourced more than 500 ooo doses for $\mathrm{PPH}-$ equivalent to a one-year supply-which arrived in the country late in 2020.

\section{Shaky distribution}

Bhatta told The BMJ that, at the time of writing, the supply of misoprostol to prevent $\mathrm{PPH}$ in pregnant women appears to be holding up. However, UNFPA said the distribution system remains shaky: "Due to the remoteness of health facilities, the commodities sometimes do not reach the site on time [to replenish stocks]," it said in a statement.

"Moreover, those who are authorised to make the requisition do not request it on time and those who are authorised to procure do not take action on time. The procurement process itself is heavily bureaucratic and time consuming. If procurement is not initiated on time, it leads to delay."

In 2021 Nepal has been hit by a second, much more intense wave of covid-19-between April and May daily cases went from 150 to more than $8000-$ fuelled by outbreaks in neighbouring India. ${ }^{3}$ Daily cases are now falling, and shortages of intensive care unit beds and oxygen easing in Kathmandu. But covid-19 is reportedly moving into rural areas, where testing and treatment capacity is limited.

Any improvements in the supply of misoprostol are likely to be challenged as the country faces further lockdowns. Asked if they are better prepared than in 2020, Pradhan at Marie Stopes says yes: "For example, as we were expecting this 'second wave' we asked our medical abortion manufacturer to pre-order active product ingredients that would last us an entire year, so we would not leave a gap in the market.”

However, UNFPA Nepal country director Lubna Baqi remembers how in 2020, births in health facilities dropped by $50 \%$ in the initial months of the covid-19 outbreak and lockdown. "Drawing from the experience last year, we must ensure that lifesaving essential services are not compromised, including access to emergency obstetric and newborn care during this second wave.”

Provenance and peer review: commissioned, not externally peer reviewed.

Competing interests: I have read and understood the BMJ policy on declaration of interests and have no relevant interests to declare.

Ashish KC, Gurung R, Kinney MV. Effect of the COVID-19 pandemic response on intrapartum care, stillbirth, and neonatal mortality outcomes in Nepal: a prospective observational study. Lancet 2020;8:E1273-81.

2 Poudel A. Fewer women are visiting health facilities for maternal services during lockdown. Kathmandu Post2020. https://kathmandupost.com/health/2020/04/28/fewer-women-are-visiting-health-facilities-for-maternal-services-during-lockdown

3 Thiagarajan K. Why is India having a covid-19 surge?BMJ2021;373:n1124. doi: 10.1136/bmj.n1124 pmid: 33931413 